\title{
Continuous Glucose Monitoring Versus Self- monitoring of Blood Glucose in Type 2 Diabetes Mellitus: A Systematic Review with Meta-analysis
}

\author{
Rajesh Naidu Janapala ${ }^{1}$, Joseph S. Jayaraj ${ }^{2}$, Nida Fathima ${ }^{2}$, Tooba Kashif ${ }^{2}$, Norina Usman ${ }^{3}$, Amulya \\ Dasari $^{2}$, Nusrat Jahan ${ }^{2}$, Issac Sachmechi ${ }^{1}$ \\ 1. Internal Medicine, Icahn School of Medicine at Mount Sinai/Queens Hospital Center, New York, USA 2. Internal \\ Medicine, California Institute of Behavioral Neurosciences and Psychology, Fairfield, USA 3. Internal Medicine, \\ Veterans Affairs Palo Alto Health Care System - Stanford University School of Medicine, Palo Alto, USA
}

Corresponding author: Rajesh Naidu Janapala, rajeshnaidu.md@gmail.com

\begin{abstract}
Every eleventh adult has diabetes, and every third has prediabetes. Over $95 \%$ of diabetics are of type 2 . It is well established that diabetes doubles the risk of heart disease and stroke apart from increasing the risk of microvascular complications. Hence, strict glycemic control is necessary. However, it increases the risk of hypoglycemia, especially in patients with longstanding diabetes. Continuous glucose monitors (CGM) use a sensor to continuously measure the glucose levels in the interstitial fluid every 10 seconds and gives out mean values every five minutes. CGMs are emerging tools in the management of type 2 diabetes. The prime objective of this review is to find out if there is enough supporting evidence, suggesting that continuous glucose monitoring is more effective than self-monitoring of blood glucose (SMBG) in type 2 diabetes. We conducted a systematic literature search in Medline (PubMed) looking for any studies addressing our objective. It is observed that there is a varying level of evidence supporting that employing a CGM can reduce glycated hemoglobin (HbA1c), hypoglycemic events, and increase patient satisfaction. However, some studies reported no significant benefits. This systematic review with meta-analysis concludes that the use of CGM in type 2 diabetes mellitus (T2DM) is beneficial, as it significantly reduces HbA1c compared to the usual method of SMBG. The pooled mean difference in HbA1c was $-0.25(-0.45,-0.06)$ and statistically significant (at $p=0.01$ ) when comparing CGM to SMBG.
\end{abstract}

Received 08/26/2019

Review began 08/30/2019 Review ended 09/01/2019 Published 09/12/2019

\section{๑) Copyright 2019}

Janapala et al. This is an open access article distributed under the terms of the Creative Commons Attribution License CC-BY 3.0., which permits unrestricted use, distribution, and reproduction in any medium, provided the original author and source are credited.
Categories: Endocrinology/Diabetes/Metabolism, Internal Medicine, Preventive Medicine

Keywords: continuous glucose monitor, type 2 diabetes mellitus, self-monitoring of blood glucose, real-time glucose monitoring, time in range, glucose variability

\section{Introduction}

The International Diabetes Federation estimates that one in every 11 adults has diabetes accounting for about 425 million diabetics in the world [1]. While the Center for Disease Control and Prevention states that the United States alone has 30 million diabetics (of whom 95\% are type 2 diabetics) and 90 million prediabetics [2]. Apart from being the leading cause of chronic kidney disease, lower-limb amputations, and adult-onset blindness, diabetes also doubles the risk of having heart disease or stroke. Diabetes is the seventh leading cause of death in the United States. The financial burden of diagnosed diabetes is projected as $\$ 327$ billion yearly, which is going to increase exponentially as the population is aging and living longer than before.

The Benefits of Continuous glucose monitor (CGM) in type one diabetic (T1DM) patients when compared to routine glucose testing have been very well established by many studies and are now a vital tool in their diabetes management. However, the benefits of CGM in type 2 diabetics (T2DM) are not well established, and its usage is limited. As most of the T2DM patients are elderly, their diabetes management is a challenge due to the co-existence of multiple comorbidities and polypharmacy. Although glycated hemoglobin (HbA1c) is a gold standard marker to assess glycemic control and a well-established marker correlating with increased complications, CGM gives the power to make the diabetes management personalized [3-4]. Though it is well demonstrated that bringing down $\mathrm{HbA} 1 \mathrm{c}$ to $<7 \%$ by an intensive glycemic control decreases the risk of microvascular complications, it is associated with an increased risk of hypoglycemia [5]. With increasing accuracy and features such as hypoglycemia alarms and trends, CGMs can reduce the risk of severe hypoglycemic events. Through this review, we wanted to know if there is enough evidence to support the efficacy of CMG over self-monitoring of blood glucose (SMBG) in patients with T2DM.

In this article, we discussed what is already known, not known, and the emerging trends in the usage of CGM in patients with T2DM. We also discussed the emerging parameters of blood glucose measurements that will potentially replace HbA1c in guiding treatment decisions. We conducted a meta-analysis compiling data from different studies to know if CGM usage can effectively reduce HbA1c in T2DM patients. 


\section{Cureus}

\section{Materials And Methods}

In this trial, we conducted a thorough and systematic literature search in MEDLINE (PubMed) through a combination of both Mesh terms and keywords. The following table details the search strategy (Table 1). The search terms were separately developed by two authors individually and combined to perform a

comprehensive search of relevant literature from the last 10 years. Studies were screened for inclusion and exclusion criteria, as mentioned below. The following figure (Figure 1) summarizes the flow of search trial through the Preferred Reporting Items for Systematic Reviews and Meta-Analyses (PRISMA) flow diagram $[6]$.

Population(P):

Article

hits

"Diabetes Mellitus"[Mesh] OR "Diabetes Mellitus, Type 2"[Mesh]

405131

AND

Intervention(l):

(("continuous glucose monitoring"[All Fields] OR "CGM"[All Fields]) OR "real-time glucose monitoring"[All Fields]) OR (continuous [All Fields] AND "measurement"[All Fields]) AND ("glucose"[MeSH Terms] OR "glucose"[All Fields])

\section{AND}

Comparison(C):

(("Blood Glucose Self-Monitoring"[Mesh] OR "self glucose monitoring"[All Fields]) OR (intermittent[All Fields] AND ("blood glucose self-monitoring"[MeSH Terms] OR ("blood"[All Fields] AND "glucose"[All Fields] AND "self-monitoring"[All Fields]) OR ("blood glucose self-monitoring"[All Fields]) OR ("self"[All Fields] AND "blood"[All Fields] AND "glucose"[All Fields] AND "monitoring"[All Fields]) OR ("self blood glucose monitoring"[All Fields])) OR "Home glucose monitoring"[All Fields]

\section{AND}

Outcomes(0):

(((()((()"Glycated Hemoglobin A"[Mesh] OR "hemoglobin A1c"[All Fields]) OR "HbA1c"[All Fields]) OR "Hypoglycemia"[Mesh]) OR "Hypoglycemic episodes"[All Fields]) OR "Hypoglycemic episode"[All Fields]) OR "low blood glucose"[All Fields]) OR "ease of use"[All Fields]) OR "convenient"[All Fields]) OR "convenience"[All Fields]) OR "user-friendly"[All Fields]

Final Search results:

TABLE 1: Search words and their combined results

MeSh, medical subject headings 


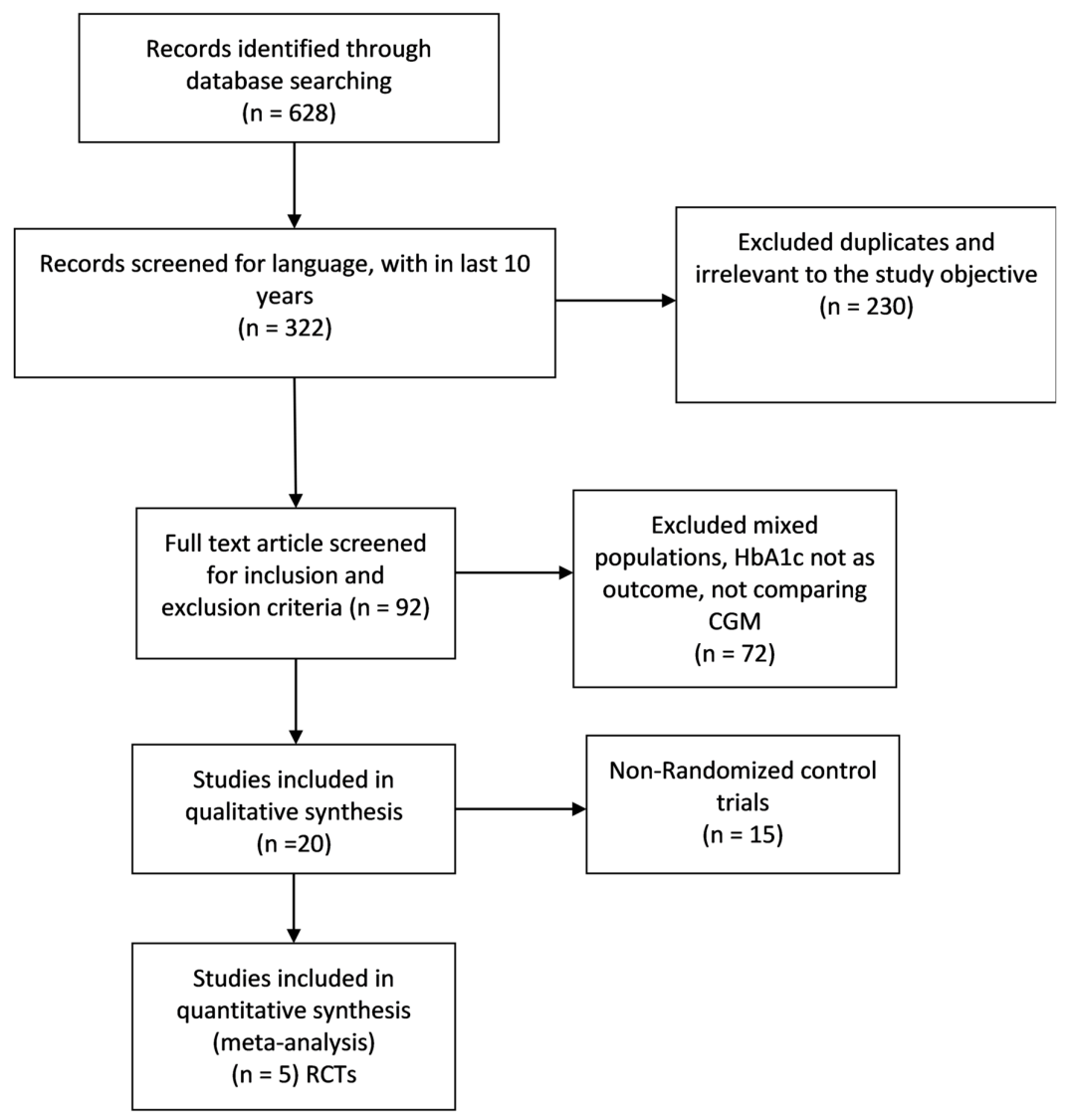

\section{FIGURE 1: Summary of study flow (PRISMA flow diagram)}

PRISMA = preferred reporting items for systematic reviews and meta-analyses, RCT = randomised controlled trial, $\mathrm{n}=$ number of results

\section{Inclusion}

1. Studies that compare CGM of blood glucose to SMBG (or other routine methods for monitoring hyperglycemia) in T2DM patient ( $\geqslant 19$ years of age)

2. Studies that measure $\mathrm{HbA} 1 \mathrm{c}$ as an outcome and has a baseline mean $\mathrm{HbA1c} \geqslant 6.5 \%$

3. Articles that are in English language or other languages if a translated version in English is readily available.

\section{Exclusion}

1. Studies involving pregnant women

2. In-patient population

\section{Statistical analysis}

The statistical analysis is planned to be carried out with Review Manage 5.3 (RevMan 5.3). The primary outcome to be measured in this review is the difference of mean HbA1c in the CGM group compared to the SMBG group at the end of the studies. In a randomized control trial, it is assumed that difference in final mean measurements will on average be the identical estimate of the difference in mean change measurements. Heterogeneity will be determined by $\mathrm{I}^{2}$ static. $\mathrm{I}^{2} 50 \%$ or more is regarded as substantial heterogeneity among the studies. A fixed-effect model will be used to combine the individual study results if heterogeneity is low $(<20 \%)$ or else the random-effects model will be used.

\section{Results}

Data extraction and quality appraisal 


\section{Cureus}

Data extracted from the randomised control trials (RCT) from our literature search are shown in Table 2.

\begin{tabular}{|c|c|c|c|c|c|c|c|c|}
\hline & \multirow{2}{*}{$\begin{array}{l}\text { First } \\
\text { author/Year } \\
\text { of } \\
\text { publication }\end{array}$} & \multirow{2}{*}{$\begin{array}{l}\text { Study } \\
\text { population }\end{array}$} & \multirow{2}{*}{$\begin{array}{l}\text { Study } \\
\text { Duration }\end{array}$} & \multirow{2}{*}{$\begin{array}{l}\text { CGM } \\
\text { usage } \\
\text { duration }\end{array}$} & \multicolumn{3}{|c|}{ Outcomes compared to control group } & \multirow{2}{*}{ Limitations } \\
\hline & & & & & HbA1c & Hypoglycemia & $\begin{array}{l}\text { Ease of use/ Quality } \\
\text { of life }\end{array}$ & \\
\hline 1 & $\begin{array}{l}\text { Beck RW et } \\
\text { al., } 2017\end{array}$ & $\begin{array}{l}n=158 \quad I=79 \\
C=79\end{array}$ & $\begin{array}{l}24 \\
\text { Weeks/six } \\
\text { months }\end{array}$ & $\begin{array}{l}\text { Daily } \\
\text { usage for } \\
24 \text { weeks }\end{array}$ & $\begin{array}{l}\text { The adjusted difference in } \\
\text { mean change for CGM } \\
\text { group and control group is - } \\
0.3 \% \text { [ } 95 \% \mathrm{Cl},-0.5 \% \text { to } \\
0.0 \% \text { ]; } \mathrm{P}=0.022 \text { ) }\end{array}$ & $\begin{array}{l}\text { Did not differ } \\
\text { meaningfully in } \\
\text { measured } \\
\text { hypoglycemia }\end{array}$ & $\begin{array}{l}\text { Did not differ } \\
\text { meaningfully in } \\
\text { Quality of life } \\
\text { measures. However, } \\
\text { the CGM group had } \\
\text { high satisfaction with } \\
\text { use of CGM }\end{array}$ & $\begin{array}{l}\text { Study duration. } \\
\text { CGM-measured } \\
\text { hypoglycemia was } \\
\text { extremely low at } \\
\text { baseline, which } \\
\text { limited the ability to } \\
\text { assess the effect of } \\
\text { CGM on reducing } \\
\text { hypoglycemia. }\end{array}$ \\
\hline 2 & $\begin{array}{l}\text { Yoo HJ et } \\
\text { al., } 2008\end{array}$ & $\begin{array}{l}n=65 \mathrm{I}= \\
32 \mathrm{C}=33\end{array}$ & $\begin{array}{l}12 \text { weeks/ } \\
\text { three } \\
\text { months }\end{array}$ & $\begin{array}{l}\text { Monthly } \\
\text { three days } \\
\text { at a time } \\
\text { for three } \\
\text { months }\end{array}$ & $\begin{array}{l}\text { Significantly reduced }(9.1 \pm \\
1.0 \% \text { to } 8.0 \pm 1.2 \% \text { vs. } 8.7 \pm \\
0.7 \% \text { to } 8.3 \pm 1.1 \% \text {, } \\
\text { respectively; } P=0.004)\end{array}$ & $\begin{array}{l}\text { No significant } \\
\text { difference between } \\
\text { the groups }\end{array}$ & $\begin{array}{l}\text { Significant reduction } \\
\text { in total daily calorie } \\
\text { intake, weight, body } \\
\text { mass index (BMI), } \\
\text { and postprandial } \\
\text { glucose level, and a } \\
\text { significant increase } \\
\text { in total exercise time } \\
\text { per week. }\end{array}$ & $\begin{array}{l}\text { Small study } \\
\text { population and } \\
\text { short study } \\
\text { duration }\end{array}$ \\
\hline 3 & $\begin{array}{l}\text { Ehrhardt } \\
\text { NM et al., } \\
2011 \text { and } \\
\text { Vigersky RA } \\
\text { et al., } 2012\end{array}$ & $\begin{array}{l}\mathrm{n}=100 \mathrm{I} \\
=50 \mathrm{C}= \\
50\end{array}$ & $\begin{array}{l}12 \text { weeks } \\
\text { of } \\
\text { intervention } \\
\text { and } 52- \\
\text { week long } \\
\text { term follow } \\
\text { up }\end{array}$ & $\begin{array}{l}12 \text { weeks } \\
\text { of } \\
\text { intermittent } \\
\text { usage }\end{array}$ & $\begin{array}{l}\text { Significant decrease in } \\
\text { mean, unadjusted HbA1c at } \\
\text { end of } 12 \text { weeks of } \\
\text { intermittent CGM usage } \\
(1.0 \% \text { vs } 0.5 \%) \text { and } \\
\text { sustained at week } \\
40(0.8 \% \text { vs } 0.2 \%)(P=0.04) \text {. } \\
\text { Average, statistically } \\
\text { adjusted Decline of } \\
0.48 \%(p=.006)\end{array}$ & Not assessed & $\begin{array}{l}\text { No difference in } \\
\text { Weight, Blood } \\
\text { pressure, and The } \\
\text { Problem Areas in } \\
\text { Diabetes (PAID) } \\
\text { scores. }\end{array}$ & $\begin{array}{l}\text { Small study } \\
\text { population, a slight } \\
\text { variation in } \\
\text { baseline } \\
\text { characteristics } \\
\text { (age) }\end{array}$ \\
\hline 4 & $\begin{array}{l}\text { Sato } \mathrm{J} \text { et al., } \\
2016\end{array}$ & $\begin{array}{l}n=34 I= \\
17 C=17\end{array}$ & $\begin{array}{l}\text { Eight } \\
\text { months }\end{array}$ & $\begin{array}{l}\text { Four to five } \\
\text { days of } \\
\text { usage on } \\
\text { three } \\
\text { separate } \\
\text { occasions }\end{array}$ & $\begin{array}{l}\text { No significant difference in } \\
\text { the change of } \mathrm{HbA} 1 \mathrm{c} \text { at the } \\
\text { end of the study }\end{array}$ & $\begin{array}{l}\text { Time spent in } \\
\text { hypoglycemia was } \\
\text { almost zero in both } \\
\text { groups both at } \\
\text { baseline and at the } \\
\text { end of the study. } \\
\text { Hence the difference } \\
\text { between the groups } \\
\text { was not } \\
\text { appreciated. }\end{array}$ & $\begin{array}{l}\text { Based on changes in } \\
\text { Diabetes Treatment } \\
\text { Satisfaction } \\
\text { Questionnaire } \\
\text { (DTSQ) scores, No } \\
\text { significant } \\
\text { improvement in } \\
\text { patient satisfaction. }\end{array}$ & small sample size \\
\hline 5 & $\begin{array}{l}\text { Cosson E et } \\
\text { al., } 2009\end{array}$ & $\begin{array}{l}n=25 I= \\
11 C=14\end{array}$ & $\begin{array}{l}\text { three } \\
\text { months }\end{array}$ & $48 \mathrm{hrs}$. & $\begin{array}{l}\text { significantly reduced (mean: } \\
-0.63 \pm 0.34 \% ; P=0.05 \text { vs - } \\
0.31 \pm 0.29 \% ; P=0.18 \text {, } \\
\text { respectively) }\end{array}$ & $\begin{array}{l}\text { No significant } \\
\text { difference between } \\
\text { the groups }\end{array}$ & $\begin{array}{l}\text { Most patients } \\
\text { reported no or mild } \\
\text { pain, while mixed } \\
\text { reporting on } \\
\text { bothersome of the } \\
\text { device due to its } \\
\text { bulkiness. }\end{array}$ & $\begin{array}{l}\text { Small study } \\
\text { population and } \\
\text { short study } \\
\text { duration }\end{array}$ \\
\hline
\end{tabular}

\section{TABLE 2: Data extracted from the RCTs}

$\mathrm{n}=$ total number of subjects, $\mathrm{I}=$ number of subjects in the intervention group (CGM group), $\mathrm{C}=$ number of subjects in the control group (SMBG group), $\mathrm{RCT}$ = randomised control trial 
Quality assessment was done in duplicate by two authors independently for all the RCTs using the latest revised Cochrane Risk-of-Bias (RoB) tool for randomized trials [13]. The summary of the risk of bias for the six randomized trials is shown illustratively in Figure 2. During the quality assessment, any discrepancy between the authors was solved after discussion with a third author. Five of the six studies shown to have a low risk of bias, while one study proved to have some concerns [7-12]. A systemic review from our search was assessed for quality with the AMSTAR checklist [14]. All other studies were evaluated for their quality using study type-specific Critical Appraisal Checklist from Joanna Briggs Institute (JBI) [15]. Each questionnaire has 10-11 questions. Each question was given one point. A study scoring five or fewer points was considered having a high risk of bias.

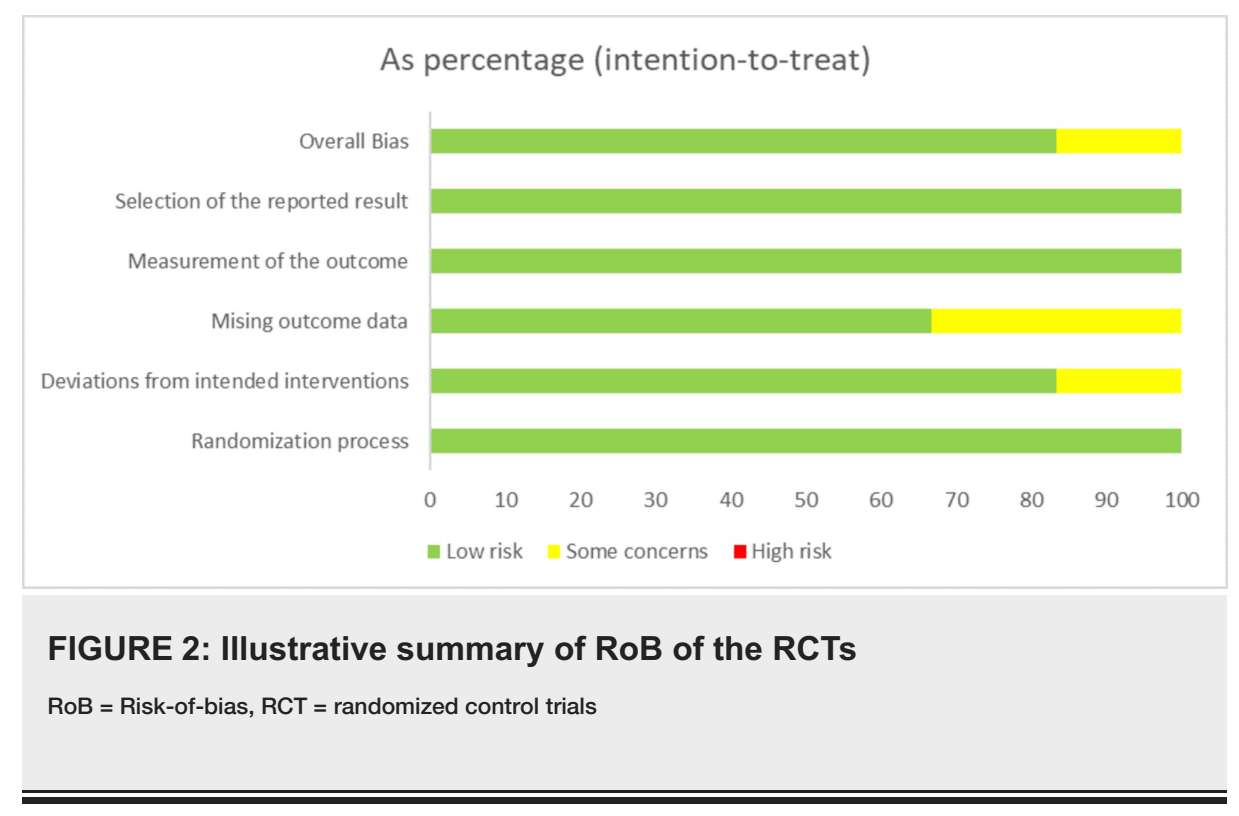

All the studies were thoroughly comprehended, and their relevant historical bibliographic references were searched for all pertinent information. After excluding studies that have data only from T1DM patients and including studies that have data from only T2DM patients or mixed population (but with subgroup data and analysis for T2DM), resulted in six RCTs. Two of these studies reported data for the same study at different time points (one after the intervention and another one after long term follow-up without intervention) [910]. Hence, only five studies were included in the meta-analysis.

The five RCTs studied 382 T2DM patients that met our study criteria with 189 patients being in the CGM group and 193 in the control group. However, in a study, three subjects in the intervention group and five subjects in the control group dropped out and were not included in that studies' final analysis [8]. Hence, our meta-analysis has 374 total T2DM patients, which include 186 in the CGM group and 188 in the SMBG group. The studies lasted in a range of three to eight months in duration. The baseline HbA1c levels ranged between $6.9 \%$ to $12 \%$. Moreover, the cumulative mean HbA1c for all the five RCTs was $8.53 \%$ (0.91) at baseline, indicating poorly controlled diabetes.

\section{Meta-analysis}

Cumulative analysis of the data from all five RCTs was done using RevMan 5 tool. The fixed-effect model was used to combine the results as the heterogeneity was very low $\left(\mathrm{I}^{2}=0 \%\right)$, suggesting minimal variation across studies. The cumulative analysis of data from all the five RCTs showed that CGM usage in T2DM patients decreased $\mathrm{HbA1c}$ by $0.25 \%$ (with a $95 \%$ confidence interval between 0.45 and 0.06 ) compared to SMBG $(p=0.01)$. The pooled mean difference in Hba1c was $-0.25(-0.45,-0.06)$ with statistical significance of $(p=0.01)$ comparing CGM to SMBG. A forest plot illustrating the same is shown in the figure (Figure 3 ). The funnel plot (Figure 4) shows that no publication bias was observed.

\begin{tabular}{|c|c|c|c|c|c|c|c|c|c|c|}
\hline \multirow{2}{*}{ Study or Subgroup } & \multicolumn{2}{|c|}{ CGM } & Total & \multicolumn{2}{|c|}{$\begin{array}{c}\text { SMBG } \\
\text { Mean [\%] SD [\%] }\end{array}$} & Total & \multicolumn{2}{|c|}{$\begin{array}{l}\text { Mean Difference } \\
\text { Weight } \\
\text { N, Fixed, } 95 \% \text { CI [\%] }\end{array}$} & \multicolumn{2}{|c|}{$\begin{array}{c}\text { Mean Difference } \\
\text { N, Fixed, 95\% Cl [\%] }\end{array}$} \\
\hline & 7.7 & 0.7 & 79 & 8 & 0.9 & 79 & $58.8 \%$ & $-0.30[-0.55,-0.05]$ & -1 & \\
\hline Sato J et al., 2016 [11] & 8.2 & 1.3 & 17 & 7.9 & 0.8 & 17 & $7.1 \%$ & $0.30[-0.43,1.03]$ & & \\
\hline Ehrhardt NM et al., 2011 [9] & 7.4 & 1 & 50 & 7.7 & 1.2 & 50 & $19.8 \%$ & $-0.30[-0.73,0.13]$ & $\rightarrow$ & \\
\hline Cosson E et al., 2009 [12] & 8.59 & 1.04 & 11 & 8.76 & 1.43 & 14 & $4.0 \%$ & $-0.17[-1.14,0.80]$ & & \\
\hline Yoo HJ et al, 2008 [8] & 8 & 1.2 & 29 & 8.3 & 1.1 & 28 & $10.4 \%$ & $-0.30[-0.90,0.30]$ & & \\
\hline Total $(95 \% \mathrm{Cl})$ & & & 186 & & & 188 & $100.0 \%$ & & $\bullet$ & \\
\hline \multicolumn{10}{|c|}{ Heterogeneity: $\mathrm{Ch}^{2}=2.46, \mathrm{df}=4(P=0.65) ; \mathrm{I}^{2}=0 \%$} & $\begin{array}{cc} & 1 \\
0 & 1 \\
\text { ] Favours [SI }\end{array}$ \\
\hline
\end{tabular}

FIGURE 3: Mean difference of HbA1c between CGM and SMBG groups at the end of respective studies and their pooled analysis 


\section{Cureus}

$\mathrm{CGM}=$ continuous glucose monitoring, $\mathrm{SMBG}=$ self-monitoring of blood glucose, $\mathrm{SD}=$ standard deviation, $\mathrm{Cl}=$ confidence interval

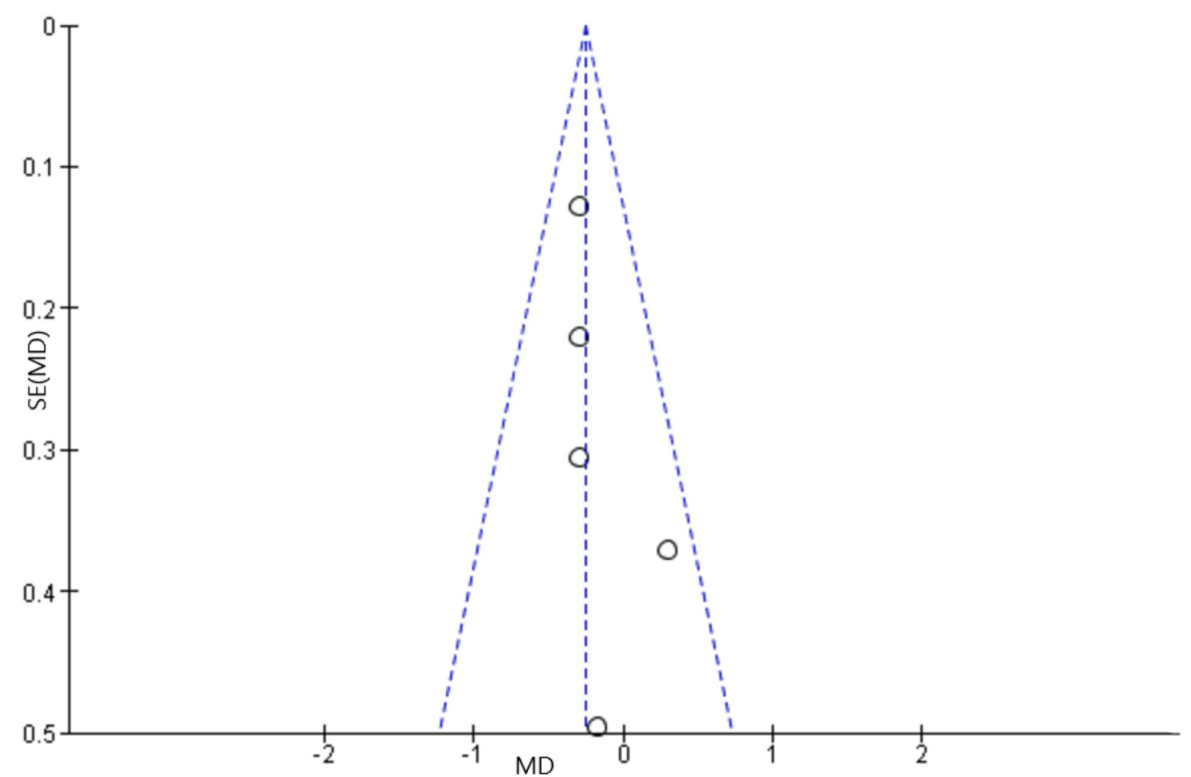

\section{FIGURE 4: Funnel plot for the five RCTs comparing CGM to SMBG in} T2DM

$\mathrm{MD}=$ mean difference, $\mathrm{SE}=$ standard error, $\mathrm{RCTs}=$ randomized control trials, $\mathrm{CGM}=$ continuous glucose monitor, SMBG = self-monitoring of blood glucose, T2DM = type 2 diabetes mellitus

\section{Discussion}

CGMs are the latest tools in the management of diabetes. The first CGM was approved by the Food and Drug Administration in 1999. Since then they kept evolving from a large device with physical wires to the sensor to present-days virtually painless small sensors that communicate wirelessly with their receivers. Current commercially available CGMs comes with different features and functions, but the main idea is that they have a sensor that is usually attached to the skin either over the abdomen or back of the arms. The tip of the sensor lies in the interstitial fluid measuring interstitial glucose level every ten seconds, then giving out an average reading every five minutes and up to 288 readings in a day, which is then transmitted to the receiver or smartphone wirelessly.

This review discusses all the aspects of CGM in type the diabetics that we came through our literature review. The CGM group or intervention group was compared to a control group that was using either an SMBG with multiple finger sticks or other routine methods. Most studies emphasized on the following areas when measuring the outcome of using CGM in T2DM patients. These include HbA1c, hypoglycemia, glucose variability, and patient satisfaction.

\section{HbA1c}

Change in the HbA1c was the primary outcome in most of the studies that focused on CGM usage in T2DM. Most studies have demonstrated a reduction in HbA1c with the use of CGM when compared to the controls $[7-10,13,16,17]$. However, a study done in a university hospital in Japan and published in 2016 demonstrated no significant change in HbA1c when compared to control [11]. It is noted that the study sample size was very small compared to other studies. In our meta-analysis, the analysis of pooled data from five RCTs showed that CGM was more effective in reducing HbA1c (mean difference of -0.25 and $95 \%$ confidence interval between -0.45 and -0.06 ) compared to SMBG with a statistical significance of more than $95 \%$ ( $p=$ 0.01). The cumulative mean HbA1c of the five RCTs was $8.53 \%$ (0.91) at the baseline, indicates that CGM was effective in T2DM patients with poorly controlled diabetes. It was observed that 14 days of CGM usage provided a reasonable estimate of mean glucose, time in range, and hyperglycemia measures for three months [18]. Collecting data for additional days did not prove to improve correlation to standard glucose metrics like HbA1c and mean glucose. Twelve weeks of intermittent usage of Real Time-CGM (RT-CGM) has shown not only to reduce HbA1c but also the effect was sustained at week 40, even after the discontinuation of CGM at 12 weeks [10]. This demonstrated that even short-term usage of CGM was beneficial, which might 
be due to the constant feedback of diet-related glucose variations resulting in patients becoming more aware of what foods to choose. This feedback mechanism leads to healthy lifestyle modification, which is very much needed in patients with T2DM.

\section{Hypoglycemia}

Hypoglycemic episodes could become a prime indication for choosing CGM by care providers in the management of their patient's diabetes. Tighter glycemic control is limited by events of Hypoglycemia. Long-standing diabetes leads to peripheral neuropathy and can reduce hypoglycemic awareness in the elderly. It is observed that in the elderly with diabetes, hypoglycemia is a more common cause for hospitalization than hyperglycemia [19]. It also increases the risk of mortality.

Studies demonstrated that CGMs detected a significantly higher number of hypoglycemic events than the SMBG or symptomatic hypoglycemia [20-23]. It is noticed that the hypoglycemic episodes were predominantly nocturnal $[17,21,22,24]$. Hence, naturally, they will go unnoticed by the patient or patient's partner, which makes the timely rescue challenging and increases the risk of mortality. CGMs with alarms to extreme glycemic excursions help in detecting impending severe hypoglycemic episodes and helps take timely action. However, it is noted that some studies have shown that CGM data did not differ significantly from the controls], which may be explained by the fact that these populations could be relatively healthy with lesser glycemic excursions [7,10,12]. Therefore, these studies have insufficient power in detecting a significant difference between the groups.

\section{Glucose variability and time in range}

HbA1c and SMBG can accurately estimate the mean glucose values, but they lack the power to look for glycemic excursions. It is observed that most hyperglycemia occurs post postprandially while most hypoglycemia occurs during the night, which is missed by T2DM patients who routinely do finger pricks in the morning and before meals. On the other hand, HbA1c only correlates with mean blood glucose levels leaving out extreme values. Additionally, studies have reported that obesity could falsely show low HbA1c [25].

Extensive glycemic data yielded by the CGMs can help overcome the above limitations. They can report the time spent in specific glycemic ranges in a day. That is, they can report the amount of time spent with glycemic levels $\leqslant 70 \mathrm{mg} / \mathrm{dl}$, between 70 and $180 \mathrm{mg} / \mathrm{dl}$ and $\geqslant 180 \mathrm{mg} / \mathrm{dl}$. Even custom glycemic ranges can be set to personalize the management. The emerging new parameter in diabetes management is Time in Range (TIR). Studies have demonstrated that CGM usage helped in increasing the time spent in TIR and decrease in time spent in hypoglycemia and hyperglycemia [7,10,26]. As of now, there is no standardized range for TIR, but the most acceptable range is between 70 and $180 \mathrm{mg} / \mathrm{dl}$ below $70 \mathrm{mg} / \mathrm{dl}$ is regarded as hypoglycemia and above $180 \mathrm{mg} / \mathrm{dl}$ as hyperglycemia. Efforts are being made to standardize the CGM metrics, including TIR, in establishing the goals for diabetes management. American Diabetic Association has presented recommendations for TIR in Type 1 and 2 diabetics as between 70 and $180 \mathrm{mg} / \mathrm{dl}$ in June 2019 [27].

\section{Patient satisfaction}

Patient satisfaction is one of the critical aspects that decide if the CGM can be used in daily life. Unlike the HbA1c (which is done once in three months) or SMBG (which is performed once or twice daily in most type 2 diabetics), a CGM device is attached to a patient's body throughout the day for 7 to 14 days or more. Unless the patients are satisfied with the accuracy, usability, and the benefits of the device, they might not be motivated to wear them. Surprisingly, one study reported very high compliance with CGM usage; about $97 \%$ of the subjects used it for six or more days per week for six months. A satisfaction survey at the end of the trial indicated very high satisfaction with CGM [26]. Some other studies also demonstrated similarly high satisfaction $[7,28]$.

One study observed that there was a significant reduction in daily calorie intake, body mass index, postprandial glucose levels, and increased exercise time per week in patients using CGM for three consecutive days within three months [10]. Real-time glucose data might serve as a motivational tool for patients, as they receive real-time feedback on their diet and exercise, encouraging them to adopt a healthy lifestyle in the long term. However, some studies reported no significant difference in weight, blood pressure, Problem Areas in Diabetes (PAID) scores, or patient satisfaction [8-9,11].

\section{Personal and professional CGM devices}

CGM devices can be classified as professional CGM devices and personal CGM devices. Personal CGM devices display real-time glucose measurements to patients. Which helps patients understand the effects of diet and lifestyle on their blood glucose levels. CGMs can act as a motivational tool and also guide medication dosage in patients using insulin. They also alert patients to extreme glucose excursions. Professional CGM devices are blinded to patients. They provide retrospective data which is mainly used by healthcare providers in making necessary changes to the patient's diabetes regimen. They are worn by the patient generally for a period of seven days, and then the data is downloaded by the healthcare provider. Professional CGM has demonstrated that it improves both glycemic control and cost outcomes in patients over a wide range of 
baseline therapies [17,29]. One study noticed that professional CGM devices provided the maximal benefit for patients with a baseline HbA1c level of 7\% or above [17]. Currently, CGM devices are expensive and are not covered by most insurance providers for T2DM. However, professional CGM devices can be cost-effective and user-friendly. Thus, they can be potentially incorporated into primary care.

\section{Limitations of CGM devices}

Like any other tool in managing diabetes CGM devices also suffer from some limitations. Currently, the most limiting factor for its integration into routine diabetic care is the cost. CGM devices are expensive and prescription only. The initial cost may exceed over $\$ 1000$ for the device, and a monthly supply of sensors may cost over $\$ 300$. Some of the devices need a fingerstick glucose test done to calibrate the CGM device frequently. This may be annoying for patients as they cannot rely on the CGM data itself, especially with extreme readings. However, the current generation of CGM devices are improving in accuracy and are factory calibrated; hence, they do not need end-user calibration. One of the prime reasons for adopting CGM devices for some patients is to manage their hypoglycemia. However, it is to be noted that CGM devices show increasingly inaccurate results at low glucose ranges. Unlike finger stick tests where the glucose levels are measured in capillary blood, CGM devices measure it in the interstitial fluid. There is a time lag of 5 to 20 minutes before the vascular and interstitial glucose levels equilibrate. Hence, they can be unreliable at times, especially during rapid fluctuations. Some people may feel uncomfortable to wear a device that is stuck on their skin all the time. Lastly, Personal CGM devices might not be beneficial merely by wearing them, without any insight and motivation to make lifestyle modifications in line with the feedback from the real-time glycemic data.

\section{Limitations of this review}

This review has many limitations. Importantly, the literature search was conducted only in one electronic database, Medline (PubMed) database. Some relevant and critical studies that are not PubMed indexed might have been missed. Studies published in other than the English language (except if their translated version is readily available) have not been reviewed. No detailed sensitivity analysis is performed due to the small sample size of the studies. No explicit cost-benefit or burden has been studied in this review.

\section{Conclusions}

The benefits of CGM in T1DM patients have been well established. However, relatively few studies have been conducted in T2DM patients, and most of them are of less than six months in duration. Although a significant amount of evidence suggests that the usage of CGM in the management of T2DM is associated with benefits of reduction in HbA1c (from our meta-analysis) especially in poorly controlled T2DM patients, the sample size and study durations are too small to generalize the results. We see the need for RCTs with larger sample sizes and longer durations to establish the above beneficial effects. The metrics of CGM have to be standardized so that they can be widely adopted into clinical practice. Guidelines for the indication of a CGM in T2DM have to be established.

\section{Additional Information \\ Disclosures}

Human subjects: All authors have confirmed that this study did not involve human participants or tissue. Animal subjects: All authors have confirmed that this study did not involve animal subjects or tissue. Conflicts of interest: In compliance with the ICMJE uniform disclosure form, all authors declare the following: Payment/services info: All authors have declared that no financial support was received from any organization for the submitted work. Financial relationships: All authors have declared that they have no financial relationships at present or within the previous three years with any organizations that might have an interest in the submitted work. Other relationships: All authors have declared that there are no other relationships or activities that could appear to have influenced the submitted work.

\section{References}

1. IDF Diabetes Atlas - 8th edition . (2019). Accessed: July 27, 2019: https://diabetesatlas.org/keymessages.html.

2. Centers for Disease Control and Prevention - Diabetes Quick facts . (2019). Accessed: July 27, 2019: https://www.cdc.gov/diabetes/basics/quick-facts.html.

3. Klonoff DC: Personalized medicine for diabetes. J Diabetes Sci Technol. 2008, 2:335-341. $10.1177 / 193229680800200301$

4. Fradkin JE, Hanlon MC, Rodgers GP: NIH Precision Medicine Initiative: Implications for Diabetes Research . Diabetes Care. 2016, 39:1080-4. 10.2337/dc16-0541

5. Diabetes Control and Complications Trial Research Group, Nathan DM, Genuth S, et al.: The effect of intensive treatment of diabetes on the development and progression of long-term complications in insulindependent diabetes mellitus. N Engl J Med. 1993, 329:977-86. 10.1056/NEJM199309303291401

6. Moher D, Liberati A, Tetzlaff J, et al.: Preferred Reporting Items for Systematic Reviews and Meta-Analyses: The PRISMA Statement. PLoS Med. 2009, 6:e1000097. 10.1371/journal.pmed.1000097

7. Beck RW, Riddlesworth TD, Ruedy K, et al.: Continuous glucose monitoring versus usual care in patients 
with type 2 diabetes receiving multiple daily insulin injections. Ann Intern Med. 2017, 167:365-74. 10.7326/M16-2855

8. Yoo HJ, An HG, Park SY, et al.: Use of a real time continuous glucose monitoring system as a motivational device for poorly controlled type 2 diabetes. Diabetes Res Clin Pract. 2008, 82:73-9.

10.1016/j.diabres.2008.06.015

9. Ehrhardt NM, Chellappa M, Walker MS, et al.: The effect of real-time continuous glucose monitoring on glycemic control in patients with type 2 diabetes mellitus. J Diabetes Sci Technol. 2011, 5:668-75. 10.1177/193229681100500320

10. Vigersky RA, Fonda SJ, Chellappa M, et al.: Short- and long-term effects of real-time continuous glucose monitoring in patients with type 2 diabetes. Diabetes Care. 2012, 35:32-8. 10.2337/dc11-1438

11. Sato J, Kanazawa A, Ikeda F, et al.: Effect of treatment guidance using a retrospective continuous glucose monitoring system on glycaemic control in outpatients with type 2 diabetes mellitus: A randomized controlled trial. J Int Med Res. 2016, 44:109-21. 10.1177/0300060515600190

12. Cosson E, Hamo-Tchatchouang E, Dufaitre-Patouraux L, et al.: Multicentre, randomised, controlled study of the impact of continuous sub-cutaneous glucose monitoring (GlucoDay) on glycaemic control in type 1 and type 2 diabetes patients. Diabetes Metab. 2009, 35:312-8. 10.1016/j.diabet.2009.02.006

13. Higgins JPT, Sterne JAC, Savović J, et al.: A revised tool for assessing risk of bias in randomized trials . Cochrane Methods 2016. Chandler J, McKenzie J, Boutron I, Welch V (ed): cohcrane library , 2016.

14. Shea BJ, Reeves BC, Wells G, et al.: AMSTAR 2: a critical appraisal tool for systematic reviews that include randomised or non-randomised studies of healthcare interventions, or both. BMJ. 2017, 358:4008. 10.1136/bmj.j4008

15. Moola S, Munn Z, Tufanaru C, et al.: Chapter 7: Systematic reviews of etiology and risk. Joanna Briggs Institute Reviewer's Manual. Aromataris E, Munn Z (ed): The Joanna Briggs Institute, Australia; 2017.

16. Poolsup N, Suksomboon N, Kyaw AM: Systematic review and meta-analysis of the effectiveness of continuous glucose monitoring (CGM) on glucose control in diabetes. Diabetol Metab Syndr. 2013, 5:39. 10.1186/1758-5996-5-39

17. Kesavadev J, Vigersky R, Shin J, et al.: Assessing the therapeutic utility of professional continuous glucose monitoring in type 2 diabetes across various therapies: a retrospective evaluation. Adv Ther. 2017, 34:1918 27. 10.1007/s12325-017-0576-X

18. Riddlesworth TD, Beck RW, Gal RL, et al.: Optimal sampling duration for continuous glucose monitoring to determine long-term glycemic control. Diabetes Technol Ther. 2018, 20:314-16. 10.1089/dia.2017.0455

19. Lipska KJ, Ross JS, Wang Y, et al.: National trends in US hospital admissions for hyperglycemia and hypoglycemia among Medicare beneficiaries, 1999 to 2011. JAMA Intern Med. 2014, 174:1116-1124. 10.1001/jamainternmed.2014.1824

20. Zick R, Petersen B, Richter M, et al.: Comparison of continuous blood glucose measurement with conventional documentation of hypoglycemia in patients with type 2 diabetes on multiple daily insulin injection therapy. Diabetes Technol Ther. 2007, 9:483-92. 10.1089/dia.2007.0230

21. Weber KK, Lohmann T, Busch K, et al.: High frequency of unrecognized hypoglycaemias in patients with Type 2 diabetes is discovered by continuous glucose monitoring. Exp Clin Endocrinol Diabetes. 2007, 115:491-4. 10.1055/s-2007-984452

22. Pazos-Couselo M, García-López JM, González-Rodríguez M, et al.: High incidence of hypoglycemia in stable insulin-treated type 2 diabetes mellitus: continuous glucose monitoring vs. self-monitored blood glucose. Observational prospective study. Can J Diabetes. 2015, 39:428-33. 10.1016/j.jcjd.2015.05.007

23. Levy JC, Davies MJ, Holman RR, et al.: Continuous glucose monitoring detected hypoglycaemia in the treating to target in type 2 diabetes trial (4-T). Diabetes Res Clin Pract. 2017, 131:161-8. 10.1016/j.diabres.2017.01.022

24. Mangrola D, Cox C, Furman AS, et al.: Self blood glucose monitoring underestimates hyperglycemia and hypoglycemia as compared to continuous glucose monitoring in type 1 and type 2 diabetes. Endocr Pract. 2017, 24:47-52. 10.4158/EP-2017-0032

25. Li J, Ma H, Na L, et al.: Increased hemoglobin A1c threshold for prediabetes remarkably improving the agreement between A1c and oral glucose tolerance test criteria in obese population. J Clin Endocrinol Metab. 2015, 100:1997-2005. 10.1210/jc.2014-4139

26. Ruedy KJ, Parkin CG, Riddlesworth TD, et al.: Continuous glucose monitoring in older adults with type 1 and type 2 diabetes using multiple daily injections of insulin: results from the DIAMOND trial. J Diabetes Sci Technol. 2017, 11:1138-46. 10.1177/1932296817704445

27. New Recommendations for Time-in-Range Targets During Continuous Glucose Monitoring Presented Today at the ADA's Scientific Sessions. (2019). Accessed: July 27, 2019: http://www.diabetes.org/newsroom/pressreleases/2019/new-recommendations-for.html..

28. Tang TS, Digby EM, Wright AM, et al.: Real-time continuous glucose monitoring versus internet-based blood glucose monitoring in adults with type 2 diabetes: A study of treatment satisfaction. Diabetes Res Clin Pract. 2014, 106:481-6. 10.1016/j.diabres.2014.09.050

29. Sierra JA, Shah M, Gill MS, et al.: Clinical and economic benefits of professional CGM among people with type 2 diabetes in the United States: analysis of claims and lab data. J Med Econ. 2018, 21:225-30. $10.1080 / 13696998.2017 .1390474$ 